\title{
Consumers' Perspective on Cab Services in Guwahati
}

\section{Saibal Kumar Saha ${ }^{1 *}$, Jupitara Kalita² and Sangita Saha ${ }^{3}$}

${ }^{1}$ Department of Management Studies, Sikkim Manipal Institute of Technology, Sikkim Manipal University, Sikkim, India

${ }^{2}$ Bachelor in Computer Application, Indira Gandhi National Open University, Sikkim, India

${ }^{3}$ Department of Management, University of Technology and Management, Shillong, Meghalaya

\begin{abstract}
Urbanization and expansion of cities add great load to the city traffic. As large number of people try to find a comfortable mode of transport, numerous minds work to provide the service and drive a business. The introduction of app based cab services and radio taxis is primarily a new concept in the Indian context. The success of such services in the metropolitan cities of India has lured the companies to start their operation in the major cities of the country and are slowly heading towards the urban and semi urban areas. The facilities and tariff rates provided by these companies are unmatched. The impatient generation of today, wish to get everything in their fingertips and these companies have provided them with just that. Now, people can book a taxi from a mobile and avail the service of transportation within minutes. The physical, laborious and time consuming job of a taxi hunt is eliminated with a search algorithm in the servers of these cab companies. The study on consumers' perspective on the cab services in Guwahati gives us a glimpse of the viewpoint of people towards the facilities provided by such companies. The lack of published literature on the topic indicated the potentiality of research in this field. Hence, personal interviews, review of published newspaper articles have been referred to get a hold over the topic and frame a questionnaire for the survey. From the survey conducted, it is seen that Uber and Ola are the prime players. People of Guwahati city are satisfied with the services of the companies but want more facilities to be provided.
\end{abstract}

Keywords: Radio taxi; Cab service; Guwahati; Ola; Uber; App Based Cab Services; Transportation

\section{Introduction}

With rapid urbanization and migration of people from rural areas to cities, the geographical area coverage of Indian cities is expanding. Large number of job opportunities, growing need of education and flourishing of trade and commerce has increased the mobility of people. The Indian transportation market is seeing a drastic change with large scale introduction of good quality buses and cabs in the streets. Air conditioned buses from manufacturers like Volvo, Marcopolo-TATA, AshokLeyland, Scania and Eicher have been introduced in the streets of India and common people are able to enjoy the pleasant rides. The ages long expectation of common people to enjoy less crowded rides of air conditioned, clean and quality vehicles for their day to day commute are also been fulfilled by the introduction of radio taxies.

The perfect blend of internet usage and smart phone penetration among the common people have been efficiently utilized to provide hassle free cab services for the common people. The ease of cab booking from remote locations and transparency of payments and tariffs have made this business model a great success. A number of companies have stated their operation of cab services in the Indian market and are tussling for a market share. Type of benefits, quality of vehicles, tariff rates, quality of drivers and promotional strategies are the major factors which differentiate one cab company from the other. Do Indian customers pay attention to these differences? Thus, this study tries to capture the perspective of customers on the cab services in the city of Guwahati and tries to throw some light on the factors which could be a decider for a customer to make his choice among the different brands available.

\section{Literature Review}

According to UNFPA [1] by 2030 more than $80 \%$ of world population will be living in urban areas. This means more number of people would be moving from one place to another and there will be an increase in demand for vehicles and more efficiency in the transportation system [2]. Trains, buses, trams and metros are the common modes of transport opted by the general public. But all these modes are inflexible, they have long travel time and lack service coverage. During extreme weather conditions or rush hours, most of these modes of transport become crowded, charge more fee and many a time do not wish to provide service. At such times, app based cab services become very useful [3].

Cost effective, well planned and efficient transportation system hold key to meet the demands of public. All these shortcomings of public transport are overcome by the taxi-cab sector. Taxi's are more convenient, fast, provide door-to-door service, are more comfortable, does not require parking fee and helps to maintain privacy. According to Moore and Balaker [4] taxis hold an important position for mobility in the transportation network of a city. Since taxis are more exclusive than other transportation services, they should be offering more than the other modes of transport. Cab services are very important for senior citizens, housewives, people who are sick, physically challenged people and those who are in an emergency.

Guwahati-the commercial hub of North-East India and the capital of Assam, is fast emerging as a multi-ethnic cosmopolitan city [5]. It is connected with various places in the region by numerous modes of transport: air, railway, waterway and road. The state capital is a hub for business and communication to different cities of the North East. The transportation system from Guwahati to different cities of the NorthEast is well developed. But, due to rapid unplanned urbanization,

*Corresponding author: Saha SK, Department of Management Studies, Sikkim Manipal Institute of Technology, Sikkim Manipal University, Sikkim, India, Tel: + 9903245847; E-mail: saibal115@yahoo.co.in

Received May 04, 2018; Accepted July 17, 2018; Published July 24, 2018

Citation: Saha SK, Kalita J, Saha S (2018) Consumers' Perspective on Cab Services in Guwahati. Bus Eco J 9: 364. doi: 10.4172/2151-6219.1000364

Copyright: $\odot 2018$ Saha SK, et al. This is an open-access article distributed under the terms of the Creative Commons Attribution License, which permits unrestricted use, distribution, and reproduction in any medium, provided the original author and source are credited. 
the transportation system for intra city is poor. The city faces a lot of problem for travelling from one part to another due to lack of proper modes of transport. Bus facilities of ASTC (Assam State Transport Corporation) and private owners are inconvenient due to their slow service and over loading of passengers. Auto-rickshaws and human powered rickshaws on the other hand charge high prices for short distances, which is again difficult for day to day travelers to pay on a regular basis.

The drawback of intra-city transportation has led to launch of radio taxis in the Guwahati city. Radio taxis has all set to capture the Guwahati market to meet the mounting transport needs of the growing city. Guwahati's population is growing day by day and the people are looking forward for fast modes of transportation within the city [6]. The radio taxis promise to strictly adhere to the transport department's fare rules and regulations as well as all safety measures [7].

\section{Radio Taxi Market Scenario in Guwahati}

There are around 10 (approx.) radio taxi companies operating in Guwahati market (TNN 2014). The prime players in the market are: Uber, Ola, Prime Cabs, Green Cabs, Pristine, Xcell and Elite. The people of Guwahati can access to $24 \mathrm{X} 7$ of their services at minimum prices [8].

The companies Ola and Uber are the major players. Prime Cabs' owner Pallav Bagaria started the business with 30 cars of Indigo and due to the growing demand of cab services 70 more vehicles were added. Ola Cabs started its operations in December 2014 with only 20 cabs [9]. The company has more than 600 cabs as of today. Due to competition between radio taxi and application based cabs new technologies are introduced in the market. A satellite based GPS tracker is used by Prime cabs to allocate the nearest available cab to the passenger in a locality within minutes of booking [10-12].

\section{Objective}

The objective of the study is to explore the perspective of consumers on the cab service of the various taxi companies functioning in the city of Guwahati, Assam.

\section{Methodology}

In order to achieve the objective of the research a survey was conducted with the help of a structured questionnaire to understand the influence of radio taxis in the mind-set of the people of Guwahati. The sample size was 50 which comprised of people who availed frequent cab services in the city of Guwahati [13]. Personal and telephonic interviews were also conducted with the employees of radio taxi service providers in Guwahati to understand the market and services from the point of view of radio taxis companies.

\section{Observations from personal interview}

- There are around 1000 cabs in the city of Guwahati.

- Customers are mainly from the corporate sector and tourists.

- The busiest route is Guwahati Airport.

- Ola cabs and Uber are the only application based cabs in the city.

- The other cabs companies fall under the category of radio taxis.

- The main difference between radio taxi and application based cabs is that the application based companies have a tie-up with the local car owners who rent their cars to the company. The drivers are provided by the company [14]. The salary of the drivers and maintenance of the cars are done by the car owners. The company charges around $20 \%$ of monthly income. Company provides the application, tracking devices and other facilities and also coordinate the entire operation. In the case of radio taxi, cars are bought by the company and then drivers are hired. Company keeps record of the travel routes.

- For the safety of passengers every Ola cab has a panic button. There is a tracking device in every taxi and the driver's background is thoroughly checked and verified before hiring. Some of the other facilities provided by Ola Cabs are online payment, lower tariff, security and proper time management.

- In Xcell cabs, police verification of the drivers are done.

\section{Observations from primary research}

Age: The survey comprised of $81.8 \%$ of respondents between the age group of $26-35$ years and $18.2 \%$ of respondents between age group of 20-25 years (Figure 1 ).

Gender: $30 \%$ of the respondents were male and $70 \%$ was female (Figure 2)

No. of times cab service taken in the past 1 year: $81.8 \%$ of the respondents reported that they have taken cab services for less than 10 times in the past 1 year, 9.1\% took the service more than 10 times but less than 20 times while only $9.1 \%$ of the respondents took the service more than 20 times in the past 1 year (Figure 3).

Occupation: $73 \%$ of the respondents worked in private sector, $9 \%$ were government employees while $18 \%$ were not working in any organization (Figure 4).

Overall satisfaction: It is interesting to note that irrespective of the service provider $100 \%$ of the respondents were satisfied with the overall cab service in Guwahati city (Figure 5).

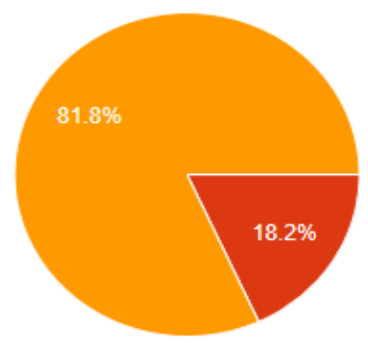

to $25 \mathrm{yrs}$ 26 to $35 \mathrm{yrs}$

Figure 1: Observations from primary research on age.

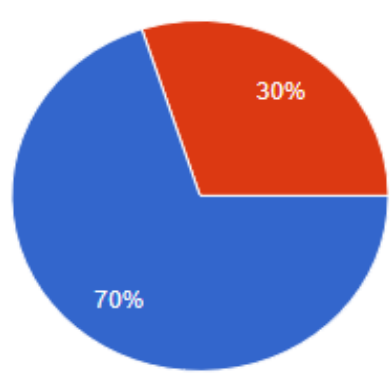

Figure 2: Observations from primary research on gender. 
Company preference: From the survey it was seen that $54.5 \%$ of the respondents preferred Ola, 36.4\% preferred Uber and $9.1 \%$ preferred Elite cab services (Figure 6).

Company facilities: It was observed that $35 \%$ of the respondents liked the proper time management which the cab services provided, $18 \%$ liked the security, $55 \%$ were happy about the tariff and $64 \%$ enjoyed the easy access facility provided by the cab companies [15].
The following responses represent the rating of respondents on a scale of 1-5 ( 1 being the lowest and 5 being the highest) for the twoleading cab service provider companies in Gawahati [16-20] (Table 1).

The problems faced by passengers from the cab services companies can be summarized as:

- Some of the drivers are irresponsible.
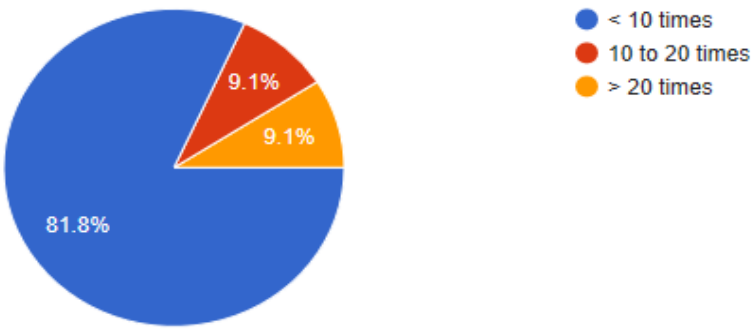

$>20$ times

Figure 3: Observations from primary research on number of times cab service taken in the past 1 year.

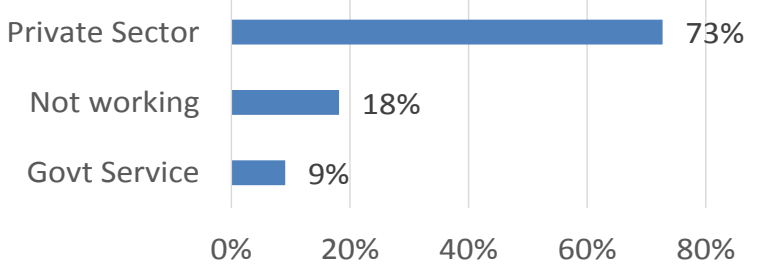

Figure 4: Observations from primary research on occupation.

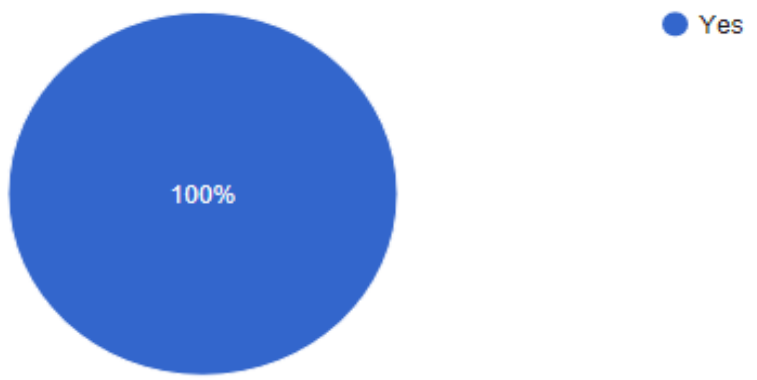

Figure 5: Observations from primary research on overall satisfaction.

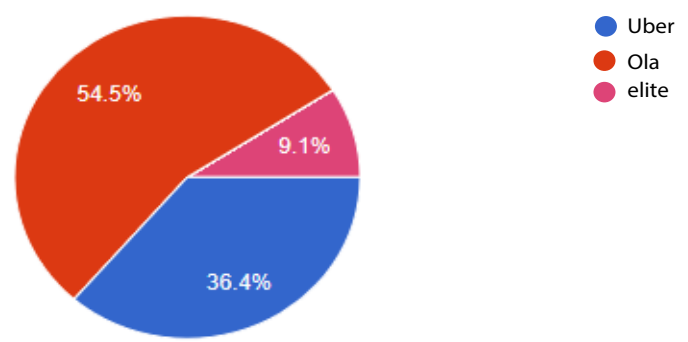

Figure 6: Observations from primary research on company preference. 


\section{Uber}

Service

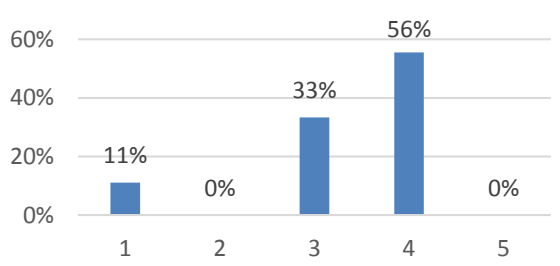

Service of Uber

$56 \%$ of the respondents gave a rating of 4 while $33 \%$ gave a rating of 3 and only $11 \% 67 \%$ of the respondents gave the rating of Ola service as 4 , $17 \%$ as 3 and 1 . So it gave a rating of 1 to the services of Uber. So, it can be concluded that the service of can be said that the overall service level of Ola cabs is good.

Uber is satisfactory but in certain cases, some of the customers faced dissatisfaction.

Quality of Cars

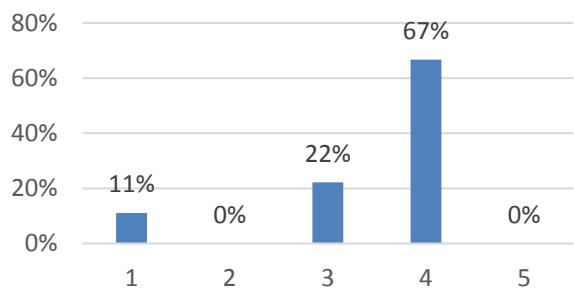

Quality of Uber cars

As per the survey, quality of Uber cars is rated as 4 by $67 \%, 3$ by $22 \%$ and 1 by $11 \%$. The survey reveals that the quality of Ola cars are good as $80 \%$ of the respondents So, it can be inferred that most of the Uber cars are of good quality while some cars gave a rating of 4 and only $20 \%$ gave a rating of 1 .

need improvement with respect to quality.

\section{Quality of Drivers}

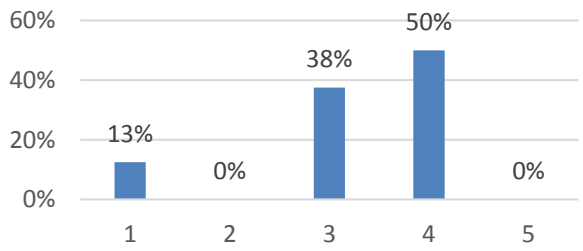

Quality of Uber drivers$$
5
$$

With respect to the quality of drivers, it is seen that $50 \%$ of the respondents gave a The quality of drivers of Ola has been rated as 4 by $60 \%$ of the respondents, 3 and rating of $4,38 \%$ gave a rating of 3 and only $13 \%$ gave a rating of 1 to the drivers of 2 by $20 \%$ of the respondents. So, we can conclude that though most of the drivers Uber cabs. Hence, we cas say that most of the Uber drivers of good barring a few. of Ola are good others need to be groomed well to meet customers' expectations. Tariff

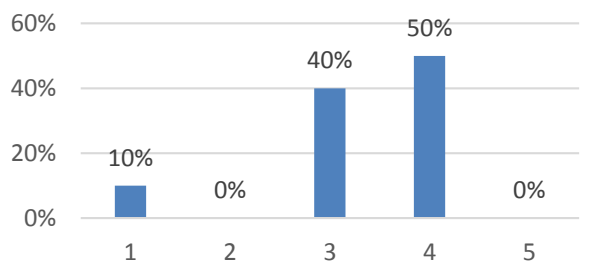

Tariff of Uber

With respect to tariff, it is seen that $50 \%$ of the respondents gave a rating of $4,40 \%$ gave a rating of 3 and only $10 \%$ gave a rating of 1 .

Hence, we can say that the tariff of Uber cabs is considered as good.

\section{Quality of Drivers}

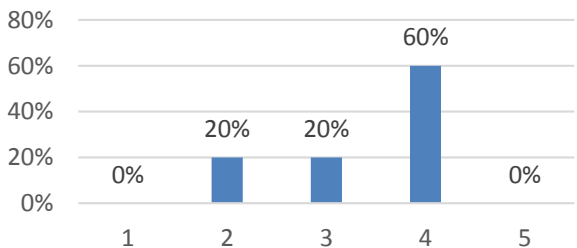

Tariff

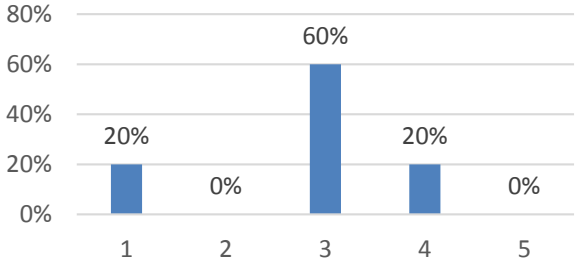

Tariff of Ola respondents has given a rating of $4.60 \%$ has given rating of 3 and $20 \%$ has given a rating of 1.

Table 1: Rating of respondents on a scale of 1-5.

- Drivers don't reach on time.

- Sometimes the drivers cancel the booking in the nick of time.

- The management of the company is not cooperative.

- Security of luggage is not taken care of properly.
Suggestions given by respondents to improve the cab service in the city are summarized as:

- Proper time management.

- Drivers should be well behaved and neatly dressed. If possible uniform should be provided. 
- Proper security system for both passenger and luggage should be implied.

- Mechanism for security alarm should be provided in every cab.

\section{Conclusion}

The cab service is a booming sector in the Guwahati market. These companies are providing better facilities than auto-rickshaws and buses. People consider the cab service as a luxurious necessity and feel justified for the tariff charged. The lack of any initiative from the Government sector in venturing into the cab business, the competition among private players can lead to better services to the passengers. Gilbert and Samuels [21] also professed that inclusion of taxis in public transit will bring innovative solutions to city's transportation problems. Security is a very sensitive area which the cab companies need to look into and ensure that the customers are satisfied with the facilities that is provided. Employment opportunities for drivers will increase with the rise in the number of taxis in the city.

\section{References}

1. UNFPA (2007) State of World Population 2007. Unleashing the Potential of Urban Growth.

2. Salanova JM, Estrada M, Aifadopoulou G, Mitsakis E (2011) A review of the modeling of taxi services. Procedia-Social and Behavioral Sciences 20: 150-161.

3. Zhang D, He T, Liu Y, Stankovic JA (2013) Call Cab: A unified recommendation system for carpooling and regular taxicab services. In Big Data, 2013 IEEE International Conference, pp: 439-447.

4. Moore AT, Balaker T (2006) Do Economists Reach A Conclusion on Taxi Deregulation? Econ Journal Watch 3: 109-132.

5. Nath SK, Raj A, Thingbaijam KKS, Kumar A (2009) Ground motion synthesis and seismic scenario in Guwahati city-a stochastic approach. Seismological Research Letters 80: 233-242.

6. Ghosh A (2015) From cabs to food delivery, Ola Cabs wants to be in all areas its technology can serve. The Huffington Post in association with The Times Group of India.
7. Bora S (2013) Radio cabs eye big business. The Telegraph.

8. Bhardwaj A, Janwalker M (2014) Uber cabs face nationalwide ban, Ola, Taxifor Sure face heat. The Indian Express.

9. Skok W, Baird S (2005) Strategic use of emerging technology: the London taxi cab industry. Strategic Change 14: 295-306

10. Maciejewski M, Bischoff J, Nagel K (2016) An assignment-based approach to efficient real-time city-scale taxi dispatching. IEEE Intelligent Systems 31: 68-77.

11. Mahapatra S, Telukoti $P$ (2018) Challenges Faced By The Uber Drivers And Consumers Satisfaction In Pune City. Global Journal for Research Analysis.

12. Bischoff J, Kaddoura I, Maciejewski M, Nagel K (2018) Simulation-based optimization of service areas for pooled ride-hailing operators. Procedia Computer Science 130: 816-823.

13. Slavnic Z, Urban S (2018) Meandering rides of the Swedish taxi industry: Flourishing entrepreneurship or ethnic segmentation? International Journal of Sociology and Social Policy 38: 444-458.

14. Kashyap R, Bhatia A (2018) Taxi Drivers and Taxidars: A Case Study of Uber and Ola in Delhi. Journal of Developing Societies 34: 169-194.

15. Razmara A, Aghamolaei T, Madani A, Hosseini Z, Zare S (2018) Prediction of safe driving Behaviours based on health belief model: the case of taxi drivers in Bandar Abbas, Iran. BMC public health 18: 380.

16. Wang Y, Li L, Prato CG (2018) The relation between working conditions, aberrant driving behaviour and crash propensity among taxi drivers in China. Accident Analysis \& Prevention.

17. Skok W, Baker S (2018) Evaluating the impact of Uber on London's taxi service: A critical review of the literature. Knowledge and Process Management.

18. Zhong-Bo G, Park UY, Lee JH (2018) Effects of Taxi-Booking Apps of E-Service Quality on Use Intention in China. The International Journal of Industrial Distribution \& Business 9: 43-52.

19. Wishart D, Evenhuis A, Mangan H (2018) Road Safety Manual for the Taxi Industry.

20. Eytan H (2018) The Space Between Us: On Shifting Sitting Patterns in Tel Aviv Taxi-Cabs, and Their Meanings. Journal of Contemporary Ethnography.

21. Gilbert G, Samuels RE (1982) The Taxicab-An urban transportation survivor Guwahati gets new cab service. Times of India. 